\title{
FINE ZNO PATTERNING WITH CONTROLLED SIDEWALL-ETCH-FRONT SLOPE
}

\author{
Jae Wan Kwon and Eun Sok Kim \\ Department of EE-Electrophysics, University of Southern California \\ Los Angeles CA, 90089-0271
}

\begin{abstract}
This paper describes a wet etching technique that solves the major difficulty of fine patterning a c-axis oriented polycrystalline $\mathrm{ZnO}$ film. The technique, for the first time, allows the $\mathrm{ZnO}$ film to be etched (1) with controlled etch rate ratio between the vertical and horizontal etch rates and (2) with controlled etch-front slope. The ratio between the vertical and horizontal etch rates is as high as 20 to 1 , while the angle between the sidewall etch-front surface and the substrate surface can be electrically controlled between $73^{\circ}$ and $106^{\circ}$. And $\mathrm{ZnO}$ films can now be patterned to fine features (even sub- $\mu \mathrm{m}$ level) by a wet etchant.
\end{abstract}

\section{INTRODUCTION}

Piezoelectric Zinc Oxide ( $\mathrm{ZnO})$ is one of most widely used piezoelectric thin films for MEMS, bulk and surface acoustic-wave resonators, acousto-optic devices, etc. [1]. For device miniaturization and/or performance enhancement, fine delineation of a $\mathrm{ZnO}$ film to sub-micron level is often needed. However, when a polycrystalline $\mathrm{ZnO}$ film is patterned by various acids and bases such as $\mathrm{HCl}, \mathrm{H}_{2} \mathrm{SO}_{4}, \mathrm{HNO}_{3}$, and $\mathrm{H}_{3} \mathrm{PO}_{4}$, it is well known that the lateral etch rate is at least several times higher than the vertical etch rate, and the etching produces a large undercut as shown in Fig. 1. The extremely high lateral etch rate in the various wet etchants has been a major difficulty for the size reduction and/or performance improvement of $\mathrm{ZnO}$-based microdevices.

In some cases, the etch-front slope of $30-40^{\circ}$ downward with respect to the wafer plane (as shown in Fig. 2) has been observed. This peculiar etch-front slope indicates that the lateral etching rate is higher near the $\mathrm{ZnO} /$ substrate interface, due to more columnar structure of the $\mathrm{ZnO}$ film at the beginning stage of the $\mathrm{ZnO}$ film deposition [1].

Among the various etchants for $\mathrm{ZnO}, 5 \%$ ammonium chloride $\left(\mathrm{NH}_{4} \mathrm{Cl}\right)$ in water at the temperature range of $55^{\circ} \mathrm{C} \sim 60^{\circ} \mathrm{C}$ is an etchant that does not attack Aluminum, silicon and silicon oxide [2], but produces the large unwanted undercuts as shown in Fig. 1. The etching rate by $5 \% \mathrm{NH}_{4} \mathrm{Cl}$ is heavily dependent on temperature: particularly, when the etchant temperature is below $20^{\circ} \mathrm{C}$, the $\mathrm{NH}_{4} \mathrm{Cl}$ hardly etches $\mathrm{ZnO}$. However, with a higher concentration of $\mathrm{NH}_{4} \mathrm{Cl}$ in water at a temperature below $20^{\circ} \mathrm{C}$ and with convective flow of the etchant, we find that we can control the vertical and horizontal etch rates as well as the etch-front slope.

We use two important properties of the $\mathrm{NH}_{4} \mathrm{Cl}$ as an etchant for fine $\mathrm{ZnO}$ patterning. One is the heavy dependency of the etch rate upon the etchant temperature and the other one is that $\mathrm{NH}_{4} \mathrm{Cl}$ is an electrolyte that is capable of producing a galvanizing flux (for batteries, for example). When a direct current is applied to a pair of copper electrodes immersed in aqueous $\mathrm{NH}_{4} \mathrm{Cl}$, water molecules are reduced at the cathode $\left(2 \mathrm{H}_{2} \mathrm{O}+2 \mathrm{e}^{-}=\mathrm{H}_{2}+2 \mathrm{OH}^{-}\right)$, producing $\mathrm{H}_{2}$ gas that produces convective flow in the etchant.

The newly invented technique for fine $\mathrm{ZnO}$ patterning is illustrated in Fig.3. Two copper plates are arranged in parallel, and act as a cathode and an anode for electrical current through $20 \%$ $\mathrm{NH}_{4} \mathrm{Cl}$ solution in an etching jar whose temperature is kept below

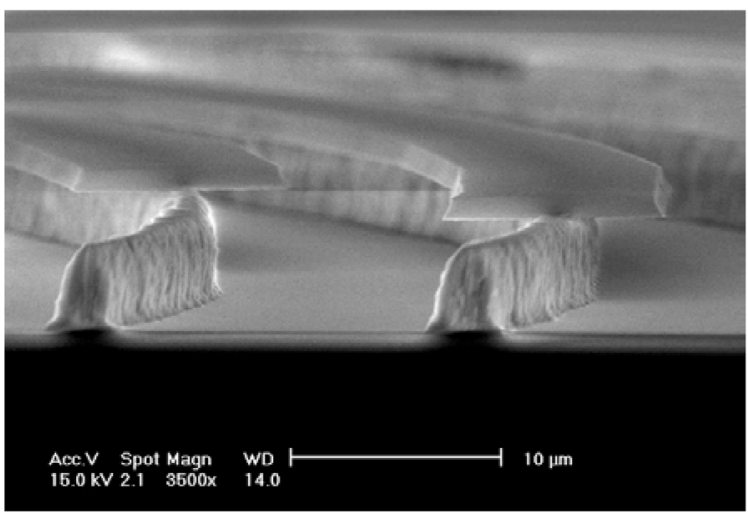

(a)

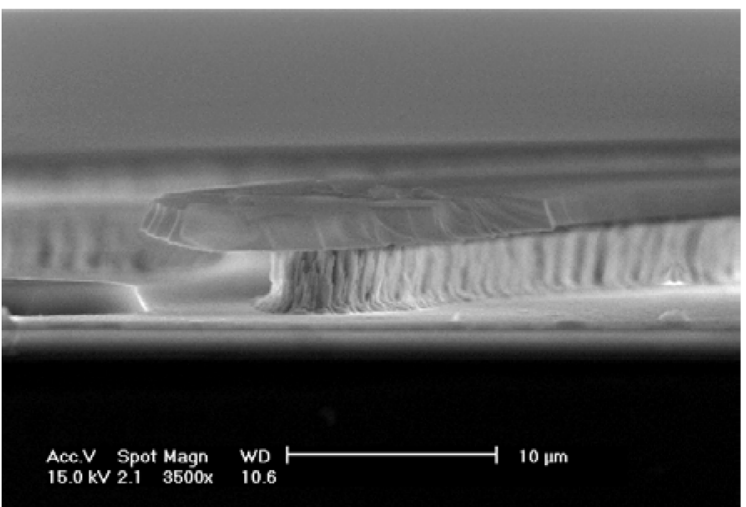

(b)

Figure 1. SEM pictures showing large lateral undercuts by various etchants: (a) after 16.5 min in $\mathrm{NH}_{4} \mathrm{Cl}$ at $55^{\circ} \mathrm{C}$, (b) after $3.5 \mathrm{~min}$ in $\mathrm{CH}_{3} \mathrm{COOH}: \mathrm{H}_{3} \mathrm{PO}_{4}: \mathrm{H}_{2} \mathrm{O}(1: 1: 30)$.

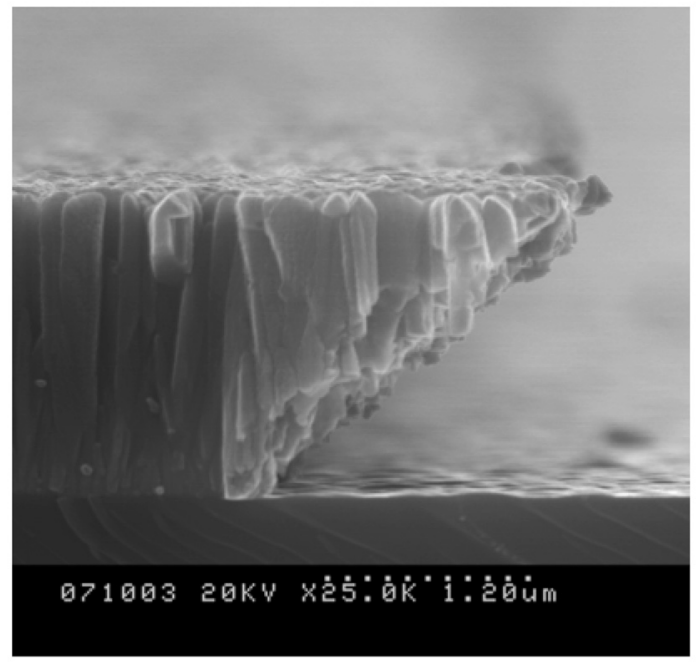

Figure 2. SEM picture of the etch front of a $2 \mu \mathrm{m}$ thick $\mathrm{ZnO}$ on $\mathrm{Si}_{x} \mathrm{~N}_{y}$ when etched in the $\mathrm{CH}_{3} \mathrm{COOH}: \mathrm{H}_{3} \mathrm{PO}_{4}: \mathrm{H}_{2} \mathrm{O}$ (1:1:30). 
$20^{\circ} \mathrm{C}$. The etch sample is $5 \mu \mathrm{m}$ thick sputter-deposited, c-axis oriented $\mathrm{ZnO}$ film on a $\mathrm{SiN}$ coated silicon wafer with patterned photoresist acting as an etch mask, and is attached to the anode copper plate as shown in Fig.3.

\section{EXPERIMENTS AND OBSERVATIONS}

\section{Experiment \#1}

We have tested with small samples $(1 \mathrm{~cm}$ by $1 \mathrm{~cm})$ and large samples (3"-diameter wafer). Various current values are applied between the anode and the cathode with a DC potentiometer.

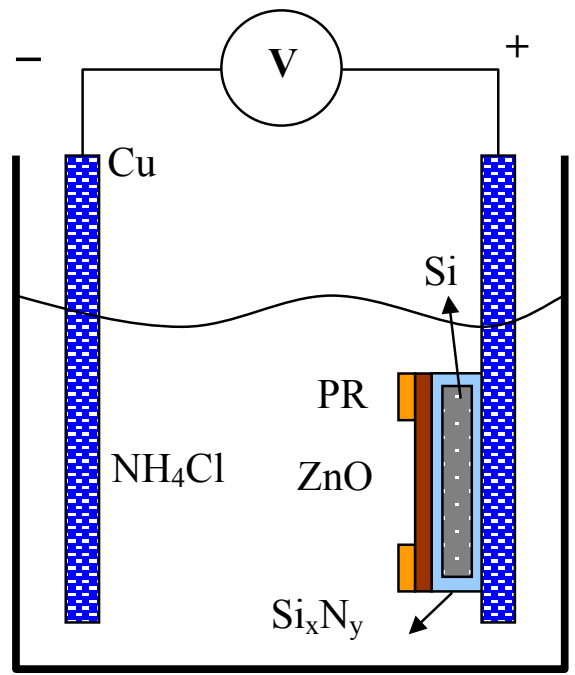

Figure 3. A newly invented technique to fine pattern $\mathrm{ZnO}$ film with negligible lateral undercut and controlled sidewall-etch-front slope.

We observe that as the etching proceeds, the surface of the cathode copper plate becomes coated with black layer of zinc and copper compound and dark brown precipitates, and also hydrogen gas bubbles form all over the cathode. The electrolyte becomes blue color because of copper ion generated by electrolysis from the cathode.

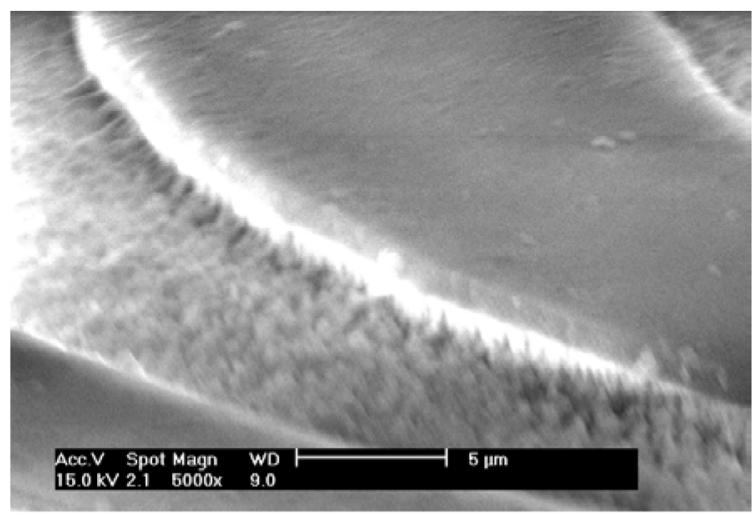

Figure 4. SEM picture taken after some $\mathrm{ZnO}$ etching to show the roughness of the etched $\mathrm{ZnO}$ surface, which indicates the directional nature of the etching.

During the etching process, at the anode, there is a strong chemical reaction in the vertical direction, as shown in Fig. 4, in which we see very rough etch-front on the exposed area compared to photoresist etch mask area. The dominant vertical etching can also be seen very clearly in Fig. 5. Vertically standing pieces of $\mathrm{ZnO}$ columnar structure represent that there is very little etching in the lateral direction comparing to the etching in the vertical direction. Figure 6 shows the shape of etch front right beneath the photoresist etch mask after the $\mathrm{ZnO}$ etching is done. The etch front is very vertical and perpendicular to the substrate and the corner beneath photoresist is very sharp.

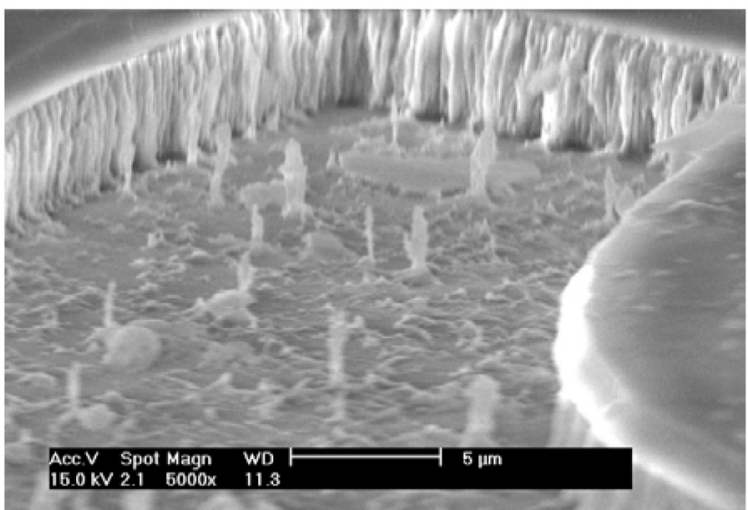

Figure 5. SEM picture taken near the end of $\mathrm{ZnO}$ etching to show vertically standing $\mathrm{ZnO}$ pieces: the $\mathrm{ZnO}$ sidewall is almost vertical and is hardly etched.

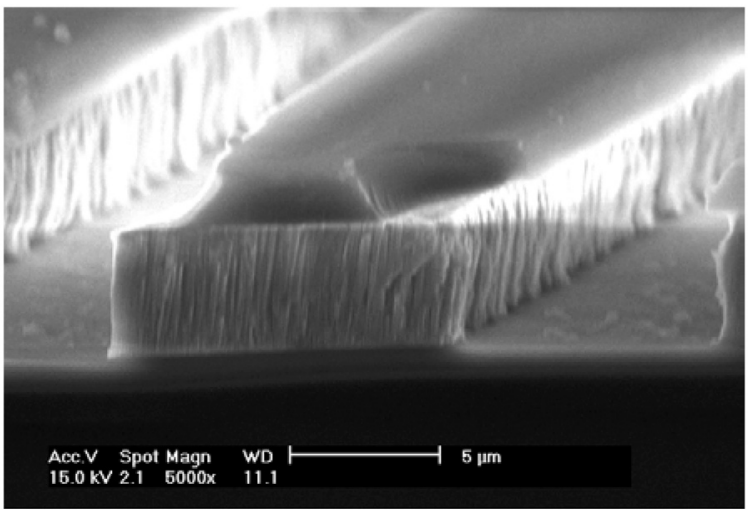

Figure 6. SEM picture of a patterned $\mathrm{ZnO}$ with partially removed photoresist.

With the new etching technique, we can now control the angle of the etch front (with respect to the substrate surface) from acute angle to obtuse angle by varying the applied current values in the etchant, as shown in Fig. 7. From the cross-sectional views, we see that the slope of the sidewall etch-front can be controlled to a wide range with the applied electrical current. With a low current of $75 \mathrm{~mA}$, the etch front is sloped at an acute angle with respect to the substrate surface (Fig. 7a). But when the current is increased to $300 \mathrm{~mA}$, the etch-front surface and the substrate surface meet at an obtuse angle (Fig. 7c), similarly to the case shown in Fig. 2. Table 1 summarizes the etching characteristics as a function of the applied current. With the current of $150 \mathrm{~mA}$, not only minimum undercut is found, but also the etch-front is straight and perpendicular to the substrate face as shown in Fig. $7 \mathrm{~b}$.

This etching technique is very useful not only for fine patterning piezoelectric $\mathrm{ZnO}$ films, but also for covering steps of etched $\mathrm{ZnO}$ films. For instance, we can intentionally produce a sidewall-etch-front as shown in Fig. 7a (or even more obliquely inclined etch-front) to cover a relatively tall step of $\mathrm{ZnO}$ with thin Al film. 


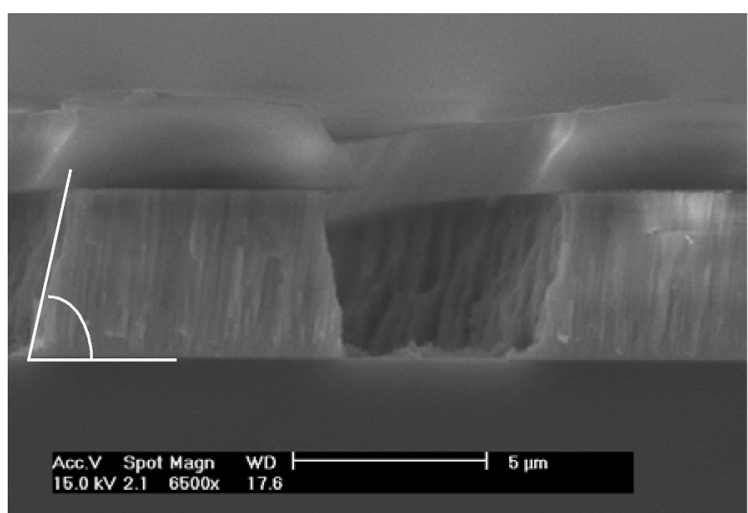

(a)

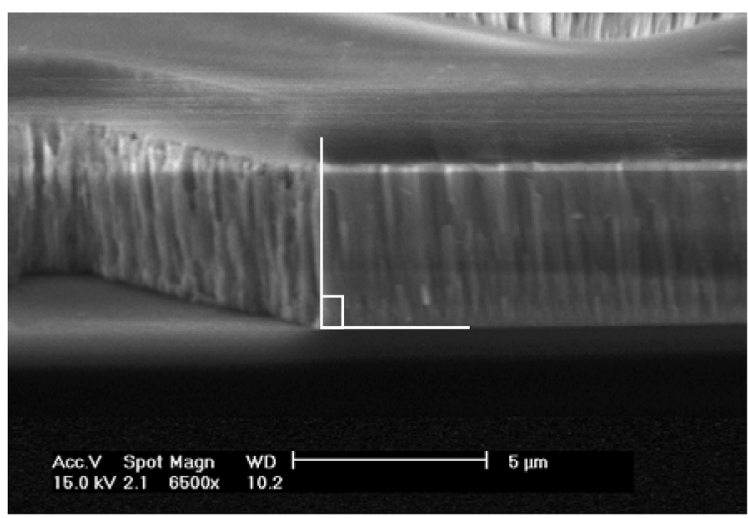

(b)

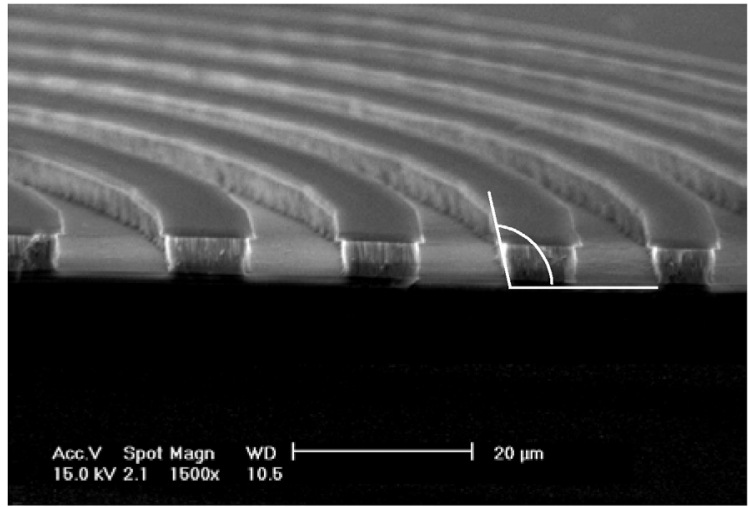

(c)

Figure 7. SEM pictures showing various sidewall-etch-front angles under various etching conditions (i.e., electrical current between the anode and cathode): (a) $73^{\circ} \sim 78^{\circ}$ at $75 \mathrm{~mA}$ (b) $90^{\circ}$ at $150 \mathrm{~mA}$ (c) $100^{\circ} \sim 106^{\circ}$ at $300 \mathrm{~mA}$.

Table 1. Summary of Etching Characteristics as a Function of Electrical Current Used during Etching.

\begin{tabular}{|c|c|c|c|}
\hline $\begin{array}{c}\text { Electrical } \\
\text { Current } \\
\text { During Etching }\end{array}$ & $\begin{array}{c}\text { Lateral Undercut } \\
(\mu \mathrm{m} \text { per } 5 \mu \mathrm{m} \\
\text { vertical etching) }\end{array}$ & $\begin{array}{c}\text { Sidewall-etch- } \\
\text { front Slope } \\
(\text { degree })\end{array}$ & $\begin{array}{c}\text { Vertical } \\
\text { Etching Rate } \\
(\mu \mathrm{m} / \mathrm{min})\end{array}$ \\
\hline $75 \mathrm{~mA}$ & 0.4 & $73 \sim 78$ & 0.19 \\
\hline $100 \mathrm{~mA}$ & 0.3 & $85 \sim 90$ & 0.21 \\
\hline $150 \mathrm{~mA}$ & 0.25 & 90 & 0.27 \\
\hline $300 \mathrm{~mA}$ & 0.4 & $100 \sim 106$ & 0.4 \\
\hline
\end{tabular}

To characterize the etching uniformity over a large area, we have tested with a 3-inch wafer in an etching apparatus similar to but larger than the one shown in Fig. 3. The etch sample is again $5 \mu \mathrm{m}$ thick sputter-deposited, c-axis oriented $\mathrm{ZnO}$ film on a $\mathrm{SiN}$ coated silicon wafer with patterned photoresist acting as an etch mask, and is attached to the anode copper plate similar to Fig.3. Though a larger amount of electrical current $(700 \mathrm{~mA})$ is applied, after 30 minutes of etching, we observe that the etching uniformity over the large area is not as good as that over the small sample. We notice that the etching rate is significantly higher near the top of the wafer than the bottom, when the wafer is placed vertically up in the etching jar, as illustrated in Fig. 8.

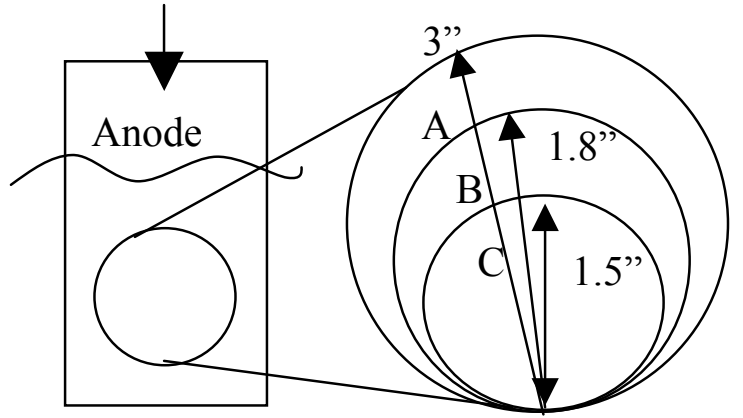

Region A: The $5 \mu \mathrm{m}$ thick $\mathrm{ZnO}$ is completely etched.

Region B: About $3 \sim 4.5 \mu \mathrm{m}$ (of the $5 \mu \mathrm{m}$ ) thick $\mathrm{ZnO}$ is etched. Region C: Only about a half of the $5 \mu \mathrm{m}$ thick $\mathrm{ZnO}$ is etched.

Figure 8. Illustration of a 3"wafer sample test for 30 minutes in the test setting \#1 and of the etching uniformity over the large area.

To resolve the non-uniformity issue, we coated the whole wafer with gold film, and opened it with square holes for the areas where we wanted the $\mathrm{ZnO}$ to etched. This is to ensure that the anode electrical current flows on the wafer surface, and the ratio between the non-conductive etch surface and the conductive anode surface is similar to that for the small sample test condition. We deposited $\mathrm{Au}$ film after an adhesion promoter, $\mathrm{Cr}$, on top of $\mathrm{ZnO}$ film, and lifted-off the $\mathrm{Au}$ film to produce $1 \mathrm{~cm}$ by $1 \mathrm{~cm}$ square openings as shown in Fig. 9. The conductive surface was connected electrically to the large anode copper plate. Thus made wafer was supposed to behave a number of small samples arranged and attached on a large anode copper plate.

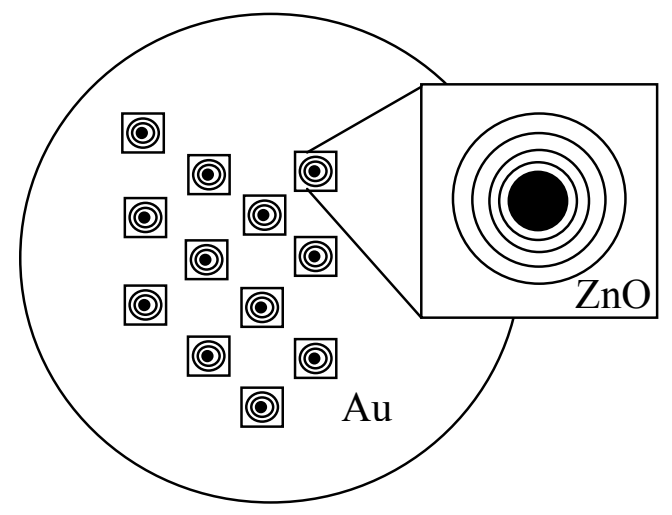

Figure 9. Illustration of a wafer covered by Au film except the square openings, where a photoresist is patterned into circular annular rings for the $\mathrm{ZnO}$ etching test.

As the $\mathrm{ZnO}$ film in the wafer shown in Fig. 9 was etched in the $20 \% \mathrm{NH}_{4} \mathrm{Cl}$ solution, the $\mathrm{Au}$ surface became mottled. In 
addition, we observed that not only the color of the $\mathrm{ZnO}$ layer changed but also the etch rate became slower, indicating that the $\mathrm{Au}$ was reacting slowly in the etchant and $\mathrm{ZnO}$.

\section{Experiment \#2}

In the large sample test in the experiment \#1, we observe that the etching is faster near the top than near the bottom of the wafer (Fig 8). At the same time we notice that there are hydrogen gas bubbles generated near the cathode, which tend to float toward the top portion of the liquid, possibly explaining why the etch rate is different at different vertical levels in the etching jar. Thus, we suspect that the poor etching uniformity over a large sample area is due to a convection flow caused by the movement of the hydrogen gas bubbles (that are electrolytically generated at the cathode).

Hence, we have carried out another experiment as illustrated in Fig. 10, in order to improve the etching uniformity, exploiting the convection flow by the hydrogen gas bubbles. From this experiment, we find that the uniformity is significantly improved on both small and large sample area. In the case of a 3 " wafer sample, we now get an etching uniformity of better than $80 \%$ over the whole 3" diameter area. The hydrogen gas bubbles are generated very uniformly at the cathode, move upward at a uniform speed, and impinge upon the whole sample area. This moderate floating movement of the gas bubbles generates a convection flow in the etchant, and seems to produce the anisotropic (i.e., vertical-etching dominated) etching characteristic. The number of the gas bubbles depends on the applied current values, and so the magnitude of convection flow can be electrically controlled. With $700 \mathrm{~mA}$ current, the etch rate $(0.47 \mu \mathrm{m} / \mathrm{min})$ with $0.7 \mu \mathrm{m}$ undercut is obtained while the etching proceeds $5 \mu \mathrm{m}$ vertically.

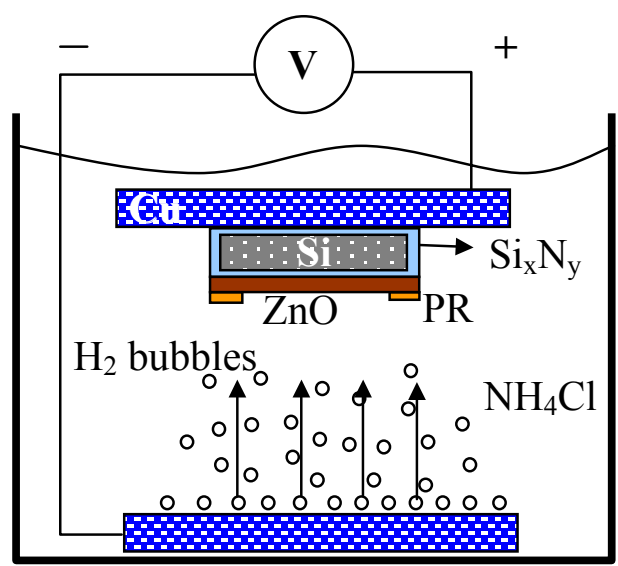

Figure 10. Illustration of the test setting for exploiting the convective flow of the hydrogen gas bubbles produced at the cathode.

\section{Experiment \#3}

To confirm that the vertical-etching-dominated etching characteristic is due to a convection flow of the etchant, we have tested a small sample in the etchant being agitated strongly at various stirring rate. The sample surface faces perpendicularly to the etch flow direction as shown in Fig. 11. At first, the flow speed is set at a similar speed with the convection flow speed in the experiment \#2. In this case, the vertical etch rate is about a half that obtained in the experiment $\# 2$, but the lateral undercut rate is two times that in the experiment $\# 2$. We find that the vertical and lateral etch rates are proportional and inversely proportional to the flow speed, respectively. And with a faster flow speed, we can obtain etch rates similar to the rates in the experiment \#2 (both the vertical and lateral etch rates). In the case of a large sample (such as a 3" wafer), a large container and a stirrer would be needed.

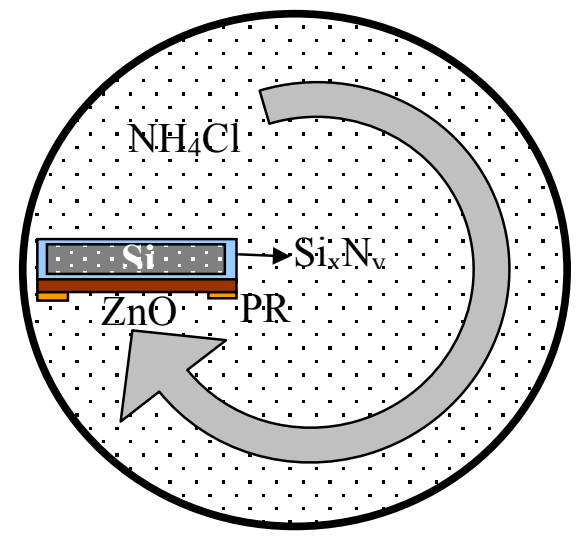

Figure 11. Illustration of the experiment confirming that the anisotropic etching characteristics by the $20 \% \mathrm{NH}_{4} \mathrm{Cl}$ solution is due to convective flow of the etchant.

\section{DISCUSSION}

Among all the different experiments described here, the best etching technique for fine patterning of $\mathrm{ZnO}$ films is the one used in the experiment \#2 (Fig. 10), since it gives best etch uniformity and highest etch rate, and also is easiest to set up. However, with the experiment \#2, the gas bubbles tend to stick and grow on the surface of the sample. The ultrasonic agitation has been proven to be helpful in preventing the bubbles from staying on the sample surface. The exact etching mechanism is not yet fully understood, but the anisotropic etching effect in an aqueous $\mathrm{NH}_{4} \mathrm{Cl}$ with a convective flow due to electrolytically generated hydrogen gas bubbles has been clearly observed.

\section{CONCLUSION}

We have newly developed a wet etching technology for fine patterning of $\mathrm{ZnO}$ thin film with controlled etch-front slope. The new technique is very useful not only for fine patterning piezoelectric $\mathrm{ZnO}$ films, but also for covering steps of etched $\mathrm{ZnO}$ films.

\section{ACKKNOWLEDGEMENTS}

This material is based upon work supported by Defense Advanced Research Projects Agency under contract \#N66001-00C-8094 and NSF CAREER Award \#ECS00-96092

Travel support has been generously provided by the Transducers Research Foundation and by the DARPA MEMS and DARPA BioFlips programs.

\section{REFERENCES}

[1] K.C. Lou, X. Zhu, H. Lakdawala and E.S. Kim, "Study on Etch Front of Piezoelectric ZnO Film and New Step Coverage Technique," IEEE International Ultrasonics Symposium (Toronto, Canada), October 5-8, 1997, pp. 565 568.

[2] S.-C. Chang, D.B. Hicks, and R.C. Laugal, "Pattering of Zinc Oxide Thin Films," IEEE Solid-State Sensor and Actuator Workshop, Hilton Head, SC, June 21-25, 1992. pp. $41-45$. 